\title{
O lócus do jovem pobre na sociedade a partir do boom dos rolezinhos
}

\section{Thiago Rodrigo da Silva}

Universidade Estadual Paulista (UNESP-Franca)

\author{
Neide Aparecida de Souza Lehfeld \\ Universidade Estadual Paulista (UNESP-Franca)
}

\section{O lócus do jovem pobre na sociedade a partir do boom dos rolezinhos}

Resumo: O presente artigo propõe uma reflexão dialética sobre a onda dos rolezinhos, iniciada em Itaquera, São Paulo, que impactou várias cidades brasileiras entre finais de 2013 e início de 2014 com reflexos ainda presentes na atualidade. Coloca-se em pauta o lócus do jovem pobre na sociedade devido ao preconceito, aos estereótipos e aos estigmas ainda enraizados no tempo presente.

Palavras-chave: Rolezinhos. Juventude. Pobreza. Lócus social.

\section{The Locus of Poor Youth in Society, Based on the Boom of "Rolezinhos"}

Abstract: This article proposes a dialectical reflection on the wave of "rolezinhos" (flash mobs by lower class youths in shopping centers) that took place in Itaquera, São Paulo, and in various Brazilian cities in late 2013 and early 2014, and whose reflections are still present. It places on the agenda the locus of the poor youth in society due to prejudice, stereotypes and stigmas that are still enrooted today.

Keywords: Rolezinhos. Youth. Poverty. Social locus. 


\section{Introdução}

Muito comum entre as gerações ${ }^{1} \mathrm{Y}^{2}$ e $\mathrm{Z}^{3}$, os "rolés" compreendem práticas de entretenimento, o qual grupos de jovens se reúnem para passeios, diversão, paqueras, visando entretenimento. A expressão "rolé" ou "rolê" surgiu na década de 1990 como uma gíria que conota as saídas para diversões. A diferença na sua grafia varia de acordo com as regiões do país, com enfoque nos estados de São Paulo e Rio de Janeiro. Ainda há controvérsias sobre seu significado e sua inserção no idioma brasileiro.

Nunca se falou tanto nesta expressão como nos últimos tempos, quando o Brasil se deparou com uma onda de "mega rolés" ou mais conhecidos como rolezinhos que se iniciou em um shopping paulistano no início de dezembro de 2013, intensificando-se e espalhando-se rapidamente para outras regiões do país facilitadas pelas redes sociais. Atualmente, a onda dos rolezinhos aparentemente se amenizou. Todavia ainda há organizações nas redes sociais que promovem estes eventos. Mesmo com esta redução do fluxo de rolés, o impacto social destes eventos foi impressionante, gerando diversas opiniões, desmascarando muitos preconceitos sociais, principalmente frente aos jovens subalternos. Os rolezinhos ganharam diversos formatos: político, sociológico, antropológico e empírico. Para os jovens, não são nada mais do que eventos que visavam à diversão, paquera, "pegação", consumo e ostentação. A análise intelectual foi mais complexa, conotando a necessidade dos jovens das camadas pobres superarem a condição de invisibilidade, agitarem a sociedade com um grito de socorro, clamando por atenção dos líderes políticos para a consolidação dos seus direitos. Estas controvérsias deixaram clara a visão social atribuída aos rolezinhos que se pautou pela seguinte imagem: a juventude pobre ou subalterna não possui os mesmos direitos constitucionais que jovens das camadas com poderes aquisitivos apropriados, devido às desigualdades sociais historicamente instituídas na nação brasileira.

Com base nesta premissa, o presente estudo, caracterizado como ensaio teórico, tem como objetivo refletir e trazer respostas para a seguinte indagação: qual o lugar do jovem pobre na sociedade capitalista contemporânea? Para esta construção, utilizamos o método dialético para dialogar e confrontar a atual realidade posta, com as reflexões empíricas e teóricas analisadas a partir de pesquisa documental e bibliográfica.

\section{Os "rolezinhos": irrupção e repercussão}

Território paulistano, cujo nome origina do tupi e significa "pedra dura", fundada em meados do século 17, bairro dormitório, espaço da colônia japonesa, alvo de um desenvolvimento industrial considerável, acolhedor, de aproximadamente 204 mil habitantes, sede da abertura da Copa do Mundo de 2014, Itaquera ficou conhecida também por ser palco de um fenômeno sociocultural ocorrido nos últimos dias de 2013: os rolezinhos.

O espaço principal foi o Shopping Metrô Itaquera (SP), que recebeu, em sete de dezembro de 2013, cerca de seis mil jovens, sendo a maioria, adolescentes de 14 a 17 anos, que, articulados via páginas de eventos e fan pages ${ }^{4}$, ambas do facebook, promoveram o maior rolê já registrado. O combinado era ouvir funk ostentação ${ }^{5}$, cantar, azarar as novinhas, consumir bens duráveis e alimentícios e se retirar.

Todavia, o impacto deste mega rolê foi reconfigurado pelo temor de lojistas, funcionários e consumidores que estavam no shopping no momento do rolezinho. Segundo informações de Ribeiro et. al. (2014), o evento foi organizado para ocorrer no estacionamento do Shopping. Contudo, com a atitude coercitiva e repreensiva da segurança do estabelecimento, os jovens adentraram ao espaço e iniciou a confusão, onde todo o público que não estava participando do evento considerou aquela aglomeração rápida como ato de arrastão, tumulto e vandalismo, situações estas que não ocorreram em Itaquera (SP).

A organização dos rolezinhos se dá da seguinte forma: um (a) jovem cria o evento na página do facebook e convida seus amigos (as) e seguidores (as). Se for popular na rede, as chances do evento ser um sucesso serão maiores. Geralmente, outro (a) jovem é convidado (a) para exercer o papel de promoter ${ }^{6}$, sendo que o critério principal é possuir popularidade no facebook. O local é definido e assim o evento é realizado. O intuito dos jovens, segundo Redação da Revista Época (2014), é tirar fotos com os ídolos ${ }^{7}$, paquerar, cantar, beijar na boca, consumir e, é claro, se ostentar. O término do evento se dá na rede social, onde será divulgado o impacto do rolezinho com a postagem de fotos dos "rolezeiros" $"$ e seus ídolos, visando ganhar maior popularidade na rede. Nada mais natural entre estes jovens que, nascidos na geração do consumo e das tecnologias de informação e comunicação, buscarem formas alternativas de sociabilidade que são, em vários casos, dificultados pela situação de pobreza e segregação aos quais estão expostos.

O antropólogo Pereira et. al., (2014, p. 2) afirma que "os jovens têm um anseio muito grande por visibilidade e expressão". Infere-se que as dificuldades da juventude subalterna em obter visibilidade na sociedade capitalista contemporânea contribuem na busca por estratégias para conquistarem o pertencimento social que tanto almejam, configurando assim suas identidades. A adolescência é a fase em que os seres humanos começam a 
construir o conhecimento de si, do mundo em que vivem, das perspectivas futuras e das pessoas que os cercam. Considerando a lógica da ostentação e da popularidade com vistas à visibilidade e expressão social, os jovens aderem aos modismos que vão nortear o processo de formatação das suas identidades.

Destacando a reflexão de Bauman (2013, p. 28), a prática do consumo interfere nas manifestações culturais, sendo que a apropriação de bens materiais auxilia a pessoa a se apresentar no seu grupo de sociabilidade. O consumo infere na formação social da pessoa e dita as regras para o desenvolvimento cultural, exigindo das pessoas, principalmente dos jovens, a variação de identidade para adequarem-se à moda atual:

A cultura plenamente abrangente dos nossos dias exige que se adquira a aptidão para mudar de identidade (ou pelo menos sua manifestação pública) com tanta frequência, rapidez e eficiência quanto se muda de camisa ou de meias. Por um preço módico, ou nem tanto, o mercado de consumo vai ajudá-lo na aquisição dessas habilidades, em obediência à recomendação da cultura.

Assim, como estratégia para seguirem a cultura vigente, os jovens utilizam da ostentação buscando meios para pertencerem à sociedade e conquistar a visibilidade esperada, mesmo que choquem a sociedade, como ocorreu nos rolezinhos. Nas palavras de Bourdieu (1989), estas estratégias são formas sociais que surgem através de um viés macrossocial, global e atinge significativamente e de diversas modalidades, grupos específicos. Os jovens mais pobres escolhem, propositalmente, os shopping centers, conhecidos como os templos do consumo ostensivo. $\mathrm{O}$ fator preocupante foi a acolhida destes templos frente aos jovens rolezeiros. A visão gerida foi a de um público que deveria permanecer no seu "habitat natural", ou seja, nas periferias. A sensação de deslocamento e de segregação não incomodou este público e, mesmo com o preconceito, manteve-se firme na dimensão ostensiva e chocante na sua presença naqueles estabelecimentos:

Diante de um simples rolezinho, a monumental empáfia das caixas-fortes do fetichismo se desfaz como fumaça. As torres inexpugnáveis, os caixotões de concreto armado, vigas de aço e vidro blindado, as fortalezas ultravigiadas que acomodam as grifes mais caras - e as mais bregas também - prometem segurança total aos clientes, mas não têm defesa contra meninos e meninas que, mesmo sem nadar em dinheiro, trafegam de cabeça erguida pelas galerias que existiriam para sentenciar sua exclusão (BUCCI, 2014, p. 2).

Os rolezinhos seriam um espaço para ostentação, diversão e azaração se não fosse a ação repreensiva da segurança pública, as solicitações de liminares no judiciário visando impedir a realização dos eventos. A mídia televisiva, virtual e impressa noticiou uma série de situações que geraram polêmicas e - a violenta reação da polícia militar, disparando balas de borracha, agressões físicas - e a privação destes jovens em exercer o direito ao entretenimento nos estabelecimentos escolhidos. O reforço das equipes de segurança nas portas dos shoppings solicitando a documentação dos consumidores jovens, as liminares solicitadas por alguns donos de shoppings e o deferimento de alguns por juízes de direito, a criminalização dos rolezinhos através da retirada de comunidades específicas ao evento das redes sociais, proibição de associar marcas famosas aos funks, retirando os videoclipes da internet (NANOMURA; SANCHES, 2014) geraram revoltas e indignações frente aos jovens e outros cidadãos. Os termos apartheid sociocultural, racismo, preconceito de classe social, a relação entre as escalas de cores (referenciando tonalidades de cor de pele) com a sociabilidade e cidadania, além da expressão "rolezinho na biblioteca ninguém promove", tomaram conta das redes sociais que movimentaram dezenas de manifestações favoráveis e contrárias à nova onda de entretenimento. Os favoráveis defenderam o direito de reunião, de manifestação pública, de ir e vir, discordando da ideia de que os shoppings são propriedades privadas, pois têm direcionamento público; outros, contrários ao fenômeno, defenderam o shopping como propriedade privada, com finalidade única. Frisaram o direito ao exercício do trabalho e atribuindo aos rolezinhos a ideia de atos de vandalismo.

Neitsch (2014) desenvolve uma reflexão quanto à legalidade dos rolezinhos. Destaca que não há amparo legal que prive jovens em promover reuniões em locais públicos. A discussão aponta sobre a concepção de público e privado em relação aos shoppings centers. Este em sua essência constitui-se em um espaço privado, porém de usufruto público, já que constitui local para consumo e entretenimento sem restrição de público alvo, ou seja, todas as pessoas, sem exceção, podem reunir-se nestes espaços para socializarem. Não existem formas de privar grupos específicos de adentrar em espaços comerciais e qualquer circunstância contrária poderá acarretar em solicitação de indenização por discriminação. Fica nítido que o ordenamento jurídico deve legislar face aos atos de vandalismo, violência e criminalidade que possam surgir em movimentos desta natureza. $\mathrm{O}$ impedimento frente ao lazer dos jovens, como discorreu nos discursos populares e liminares judiciais, não podem ser alvos de represálias legais, pois não há ilegalidade em organizar e promover eventos via redes sociais. 
Este trabalho localizou decisões judiciais favoráveis e contrárias à prática dos rolezinhos. A primeira, referendada pelo Juiz de Direito do Foro de Itaquera, Carlos Alexandre Bottcher, especifica a petição do Consórcio Shopping Metrô Itaquera (SP) que registra que um grupo de pessoas, sem personalidade jurídica, conclama em redes sociais várias pessoas para se manifestarem em locais privados e públicos e que este público é de difícil identificação. O requerente da petição ainda se baseou em atos delitivos ocorridos aleatoriamente durante o primeiro rolezinho de dezembro de 2013. Estes atos não estavam previstos pelos organizadores do evento, havendo, neste caso, um aproveitamento da situação, da aglomeração de pessoas, para os delitos. $\mathrm{O}$ referido magistrado pautou-se em atitudes aleatórias para analisar de forma genérica todo um grupo de jovens que se reuniram, até então, de forma pacífica para o lazer. Conforme já destacado, observa-se que a organização geral do rolezinho não previu em nenhum momento atos de criminalidade. A decisão judicial determinou uma medida liminar de ato proibitório que não vetou a realização dos rolezinhos agendados após 07/12/2013, mas referendou orientações para a manutenção da urbanidade e civilidade no estabelecimento.

Observa-se uma visão que criminaliza o exercício dos jovens das classes subalternas em praticar o lazer e promover seus eventos da forma que desejarem. Houve uma generalização dos atos ocorridos simultaneamente (criminalidade e diversão) e os demais jovens, não envolvidos em atos infracionais, também tiveram que receber as orientações. Percebe-se uma clara criminalização da pobreza, da juventude pobre, da cultura da periferia, pois, conforme Neitsch (2014) exemplifica de forma análoga, nunca foi enviada a jovens de classe média alta de Curitiba qualquer liminar que restringisse ou privasse-os de realizar seus famosos réveillons fora de época.

Já o Juiz de Direito do Foro de Campinas (SP), o Sr. Herivelto Araújo Godoy, cita na decisão que o Condomínio Civil do Shopping Center Iguatemi Campinas, situado no interior do estado de São Paulo, requerente na petição, alega o agendamento do rolezinho para a realização de um aniversário e que este evento aglomeraria um grande número de jovens e afirma que as finalidades nem sempre são bem definidas. Julga improcedente deferir tal solicitação, pois não são encontrados requisitos que provem a ilegalidade e a criminalidade do evento organizado. A compreensão do juiz referente ao evento demonstra a compreensão que a realização do rolezinho no Shopping Iguatemi Campinas (SP) seria usado como pretexto para práticas delitivas. Afirma também que não é possível considerar apenas as infrações cometidas em outros eventos já realizados em outras cidades como base de sustentação para deferimento de interdição proibitiva, visto que há o lado satisfatório dos eventos, que em sua finalidade e realização, atingiram o seu objetivo, que era o lazer. A decisão final foi o indeferimento da medida liminar, determinando a cautela na realização do evento, oficiando a Polícia Militar (PM) a enviar efetivo para resguardar a segurança de todos os consumidores do shopping incluindo os jovens rolezeiros, deixando clara a importância da PM firmar compromisso de proteção aos próprios jovens que poderiam participar do rolezinho.

Assim, não foi perceptível a visão preconceituosa e criminalizadora na leitura da decisão judicial do Foro de Campinas. O juiz mostrou visão sensata da questão tão polêmica e frisou que não é possível generalizar atitudes e movimentos sociais, pois cada situação representa fatos peculiares que devem ser analisados com cautela, pautando-se sempre pelas legislações vigentes, com destaque na Constituição Federal e no Estatuto da Criança e do Adolescente.

Segundo o levantamento de processos de petições de interdições proibitórias realizado por Rover e Scocuglia (2014) no início do ano de 2014, não houve nenhuma proibição de realização de rolezinhos nas Comarcas pesquisadas, de São Paulo e do Rio de Janeiro, porém, deferiram algumas restrições que deixam transparecer que a visão técnica e jurídica sobre os rolezinhos foram divergentes devido aos olhares singulares de cada juiz.

O rolezinho significa um evento legítimo e legal, quando promovido com fins de entretenimento ou manifestação pacífica, conforme preconiza os direitos fundamentais da Carta Magna de 1988. A criminalização dos rolezinhos abarca questões étnicas e raciais. Ataca, principalmente, o pertencimento da juventude em estratos sociais inferiores, invisíveis nos templos do consumo e julgados quando adentram a estes espaços, buscando visibilidade e igualdade no direito de consumir e usufruir aquilo que adquiriram. A polêmica se fez presente e forte porque o Brasil ainda é uma nação que discrimina as classes mais pobres, criminalizando-as e banalizando-as, atribuindo valorização aos membros da "nobreza brasileira" que possuem ideais higienistas e segregacionistas.

\section{Direito de reunião, pobreza e juventude}

Aplicar leis para conduzir a sociedade a um desenvolvimento harmônico e organizado não é tarefa fácil; se não for bem elaborada, cada cidadão a interpretará de forma peculiar. Rousseau já dizia, no século 18, que o elaborador das leis é a pessoa mais indicada para apresentá-la e interpretá-la. Entretanto, os seguidores também precisam saber interpretá-la adequadamente. Importante observar o direcionamento das leis e suas implicações no cotidiano das pessoas, pensando na reação dos cidadãos frente a ela. Geralmente, leis e normas 
surgem para nortear a dinâmica de uma sociedade de forma democrática ou arbitrária, podendo acarretar em reações preocupantes. Pensa-se que as leis que regem a sociedade são mais eficazes do que aquelas criadas para submeter as pessoas à vontade soberana dos governantes: "Sempre haverá grande diferença entre submeter uma multidão e reger uma sociedade" (ROUSSEAU, 1996, p. 19). É claro que o espaço democrático para discussão e consenso não discorre em plena concordância, tampouco agrada a todos os envolvidos. É necessária a implantação de um contrato social que oriente a todos a não viver sua liberdade e independência sem se importar com os demais. Vamos reportar essa reflexão para a presente discussão sobre o direito de reunião pacífica associada à prática dos rolezinhos, discutido durante a transição anual de 2013-2014, período de maior intensidade do referido fenômeno.

É fundamental reiterar que os rolezinhos foram reuniões organizadas por jovens, em sua maioria, oriundos das classes subalternas com o intuito de promoção de lazer voltado ao consumo, paquera, à escuta de funk

... a prática do consumo

interfere nas manifestações culturais, sendo que a apropriação de bens

materiais auxilia a pessoa a

se apresentar no seu grupo de sociabilidade. $\mathbf{O}$ consumo infere na formação social da pessoa e dita as regras para 0 desenvolvimento cultural, exigindo das pessoas, principalmente dos jovens, a variação de identidade para adequarem-se à moda atual. ostentação e diversão com os ídolos virtuais. O direito de reunião está previsto na Constituição Federal e compreende em um direito fundamental (Artigo $5^{\circ}$ ) que visa a liberdade das pessoas se reunirem pacificamente, sem o levante de armas em locais abertos ao público: "Artigo 5, Inciso XVI todos podem reunir-se pacificamente, sem armas, em locais abertos ao público, independentemente de autorização, desde que não frustrem outra reunião anteriormente convocada para o mesmo local, sendo apenas exigido prévio aviso à autoridade competente" (BRASIL, 2013). Destacando a expressão "locais abertos ao público", é possível afirmar as divergências de ideias em relação aos shoppings centers, pois quando foram solicitadas as petições e expedidas as liminares restringindo as atividades dos rolezinhos, divulgouse que os estabelecimentos são de caráter privado, não permitindo assim a realização das reuniões.

Entendemos que os shoppings são sim estabelecimentos privados, porém não restringe o público que os frequenta, pois são locais abertos ao consumo e lazer e que deve aceitar todos os públicos, sendo que qualquer restrição descabida pode acarretar em processos indenizatórios por preconceitos e discriminações. Deste modo, as liminares restritivas feriram o direito constitucional de reunião, pois os embasamentos utilizados discriminaram jovens que não tiveram envolvimento em atos delitivos e vandalismos. Concebeu-se, por parte dos juízes, uma generalização dos rolezinhos e dos jovens participantes frente à criminalidade. A Declaração Universal dos Direitos Humanos, de 1948, também expressa como um direito humano a organização em grupos para reuniões: "Artigo 20; Item 1. Todo ser humano tem direito à liberdade de reunião e associação pacífica” (UNESCO, 1998, p. 03). Pautando-se pela Carta Magna e pela Declaração dos Direitos Humanos, infere-se que os jovens rolezeiros não feriram princípios legais ao organizarem os eventos e assim realizá-los. Além dos aspectos delitivos que ocorreram durante os rolés, outra questão que chamou a atenção dos gestores dos shoppings, da segurança pública e dos juristas foi o poder das redes sociais e a fácil articulação entre os jovens que, em poucos dias, reuniram centenas de pessoas nos rolezinhos.

Martín-Barbero (2008, p. 23) destaca que a internet consiste em um espaço virtual de sociabilidade que está intrínseca nos contatos físicos entre os jovens. Ele diverge de estudos que afirmam o isolamento juvenil pela virtualização das relações sociais apontando para a soma da tecnologia nas relações juvenis: "Em nossos países, a juventude que usa frequentemente a internet segue igualmente frequentando a rua, curtindo festas nos finais de semana e preferindo a companhia ao isolamento". Há assim uma dependência das relações físicas com as virtuais, pois uma complementa a outra nos contatos entre os jovens tal como nos rolés. O contato inicial se dá via facebook ou outras redes, depois há a presença física em determinado espaço e o evento se encerra na rede social para promover os resultados do evento. Jovens anseiam em inserirem-se em grupos, viver socialmente com outras pessoas, desejam ser reconhecidos e pertencidos nos espaços em que escolhem conviver. Deste modo, o direito de reunião deve ser garantido e fortalecido para este grupo, principalmente os jovens pobres que mais sofrem com estereótipos historicamente constituídos. 
Os rolezinhos iniciaram carregados de estereótipos e o consenso social firmado para este foi a sua criminalização. Catani e Gilioli (2008) apontam que as juventudes ao longo das décadas firmavam-se em grupos para finalidades diversas. Os autores esclarecem que a partir das décadas de 1980, com extensão para as décadas seguintes, houve uma preocupação dos jovens de estratos sociais menos favorecidos em associarem-se para a prática do consumo, buscando pertencimento social e acompanhar as mudanças sociais promovidas pelo sistema capitalista. Nesta perspectiva, pensa-se na reavaliação da concepção de reunião, já que na própria Constituição Federal não há especificidades quanto ao significado de se reunir pacificamente. Durante os rolezinhos muitos se apropriaram de reuniões conotando-as como manifestação popular, luta social e protestos. Pois bem, é compreensível que estes significados estejam adequados, entretanto, respeitando a concepção juvenil de reunião para diversão, é importante que haja esclarecimentos e informações sobre o que podem ser e como podem ser discorridas as reuniões pacíficas. As reuniões devem ser consideradas como toda associação de pessoas, independentemente de suas singularidades que, constituindo em grupos, promovem eventos de naturezas diversas cuja finalidade corresponde às intenções iniciais destes grupos. As reuniões podem ter características militantes, políticas, lúdicas, reivindicativas, educativas, culturais, religiosas, sociais que, exercidas sob a ótica pacífica e não discriminatória, podem ocupar-se de espaços públicos e espaços de uso público para promoverem suas atividades, utilizando do bom senso para escolher locais apropriados para cada tipo de reunião.

Quanto aos rolezinhos, é importante que haja uma desconstrução dos estigmas criados, de modo a dignificar os jovens das periferias; resignificar a visão do jovem pobre que ainda é associado à criminalidade, ao vandalismo como um tipo de "mal elemento" que deve ser exterminado da sociedade, ou nas palavras de Scherer (2013), retirar do jovem da periferia o papel de vilão imposto pela sociedade durante sua história de formação. Visando a garantia e a proteção digna dos jovens, em especial da juventude pobre, é importante que as análises que têm sido realizadas acerca dos rolezinhos pautem pela sua descriminalização, pois ficou nítido o preconceito frente a este evento e mais nítida ainda ficou a criminalização da juventude pobre (MARTÍNBARBERO, 2008), considerados como seres desviantes e rebeldes que necessitam de atenção policial. Sabese que a dimensão social destes jovens vai além da realidade visível; perpassa os aspectos mais complexos como a formação e desenvolvimento histórico das população pobre e os impactos em suas gerações, questões sociais, políticas e culturais que interferem no desenvolvimento biopsicossocial das pessoas, principalmente destes sujeitos pela sua situação peculiar de desenvolvimento e crescimento.

\section{Considerações Finais}

O fenômeno dos rolezinhos "não era um protesto contra os males do mundo, era uma forma de procurar espantá-los por algumas horas de forma segura, alegre e num ambiente valorizado pelos desejos de consumo" (SERRANO, 2014, p. 01). Esse era o desejo dos adolescentes rolezeiros, que buscaram um espaço de diversão, paquera e promoção do status social, visto que em seus territórios não possuem muitas opções de entretenimento.

É importante destacar a imagem dos adolescentes e suas peculiaridades sociais, emocionais e biológicas. O estudo de Lopes (2002) registra a importância de compreendermos a juventude para além de aspectos objetivos. O autor fala que a subjetividade do ser adolescente e suas expressões psicossociais têm muito a dizer sobre eles, podendo contribuir com a implantação de políticas públicas eficazes de atendimento e garantia de direitos à juventude.

Desse modo, frisaram-se nesse trabalho os aspectos sociais da juventude subalterna, fazendo alusão ao estudo de Yazbek (2009), pois este público está subordinado a uma hegemonia econômica dominante, o sistema capitalista, e com ele o Estado, falho em suas responsabilidades e a favor do capital financeiro. A dinâmica social do sistema capitalista contemporâneo tem fragmentado os direitos dos cidadãos pobres, desqualificando e criminalizando-os. A desigualdade social vigente hoje ainda mostra que as ações governamentais não têm sido suficientes. Conforme verbaliza Bauman (2013), o acesso e aumento da renda não são fatores exclusivos para nivelar a igualdade social, pois os valores de renda, formas de obtenção, produção e acumulação de riqueza e de distribuição de renda nada equitativa apenas favorecem a manutenção ou ampliação das desigualdades.

Neste bojo, a adolescência subalterna sofre violências sociais e psicológicas quando buscam visibilidade e pertencimento sem subsídios adequados. Sob a análise de Singer (2011), os jovens da contemporaneidade, mais empáticos às questões de desigualdades de oportunidades, possuem uma visão de solidariedade e igualdade de oportunidades entre as pessoas. A possibilidade de conseguirem se criar e viver/sobreviver em um espaço mais digno, com respeito entre as pessoas, sem qualquer distinção, são os maiores anseios dos jovens. Porém, o cenário atual é o inverso. As classes abastadas vêm criminalizando a juventude subalterna e todas as suas manifestações sociais, políticas e culturais. É notável a visão segregacionista e discriminatória às classes pobres, contradizendo 
na totalidade o preconizado no caput do Artigo $6^{\circ}$, da Constituição Federal, que diz que "todo ser humano tem o direito de ser, em todos os lugares, reconhecido como pessoa perante a lei" (BRASIL, 2013).

Todo este aparato de violência, discriminação, criminalização da pobreza e dos seus jovens, além da miséria, das desigualdades e de políticas ineficazes foram perceptíveis na onda dos rolezinhos. Quem teorizou que o fenômeno correspondeu ao grito juvenil pelo fim do racismo e do preconceito de classe se enganou. Quem intensificou as discriminações foram os atores sociais que apontaram julgamentos aos eventos organizados e realizados. Quem atribuiu aos rolezinhos a condição de vandalismos, praticou uma concepção social violenta face aos jovens pobres; quem criticou a popularização dos produtos de grife assinou o acordo pleno de segregação social que visa uma sociedade urbana higienizada e livre das populações periféricas.

Os rolezinhos foram tão impactantes que as repercussões internacionais foram das mais variadas, todas apontando para os problemas sociais do Brasil e a falta de oportunidades e políticas para os jovens pobres. Segundo a Redação da Revista Época (2014), jornais e revistas como a Bloomberg (Nova Iorque, EUA), The Atlantic (Boston, EUA), New York Times (Nova Iorque, EUA) e El Pais (Madri, Espanha) descreveram os rolezinhos como: eventos causados pela falta de espaços públicos de lazer, destacando a cultura da periferia associada ao funk ostentação, afirmando que os jovens, mesmo pobres, estão mais interligados ao capitalismo; críticas às liminares impediu parcialmente a prática dos eventos, apontaram a questão do preconceito e a visão de que o jovem da periferia não tem espaço para se socializar e expressar sua identidade pessoal e cultural; apontamentos sobre a repressão dos rolezinhos por mera discriminação de classe social e racial; repressão das expressões juvenis nos shoppings, com a reflexão sobre o pertencimento dos templos do consumo e o lugar da juventude pobre nestes espaços elitizados.

O histórico dos rolezinhos, suas repercussões em âmbito nacional e internacional, as interpretações atribuídas aos eventos, os discursos políticos carregados de preconceitos e estereótipos somadas aos direitos hoje garantidos e pouco exercidos, mostram que o Brasil se identificou e assumiu a postura de nação preconceituosa, deixando a máscara da política da boa vizinhança cair por terra, fazendo transparecer o repúdio pelas classes pobres, principalmente pelos seus jovens, brancos, negros, trabalhadores, desempregados, estudantes, evadidos das escolas, com vida dentro da lei e outros envolvidos em atos infracionais (SILVA; LEHFELD, 2014). A criminalização do jovem por ser pobre e de periferia, sua expressão cultural e suas formas de entretenimento estarreceram uma parcela da população que identificou este jovem como perigo social e caso de polícia, prejudicando assim o debate acerca dos direitos, das políticas públicas e da igualdade social neste país. O Brasil vive uma contradição social: é plural e diversificada em sua história étnica/racial e sociocultural, porém tem sido preconceituosa por valores e morais historicamente estabelecidos. Vive-se um período de crise social o qual se fortalece a concepção de que dignidade e condição da pessoa como ser humano possuem como critério de pertencimento social a cor de pele e nível de classe social.

\section{Referências}

ABRAMO, H. W. Condição juvenil no Brasil contemporâneo. In: ABRAMO, H. W.; BRANCO, P. P. M. Retratos da juventude brasileira: análises de uma pesquisa nacional. São Paulo: Fundação Perseu Abramo e Instituto Cidadania, 2011, p. 37 - 72.

ALVES, G. Trabalho, subjetividade e lazer: estranhamento, fetichismo e reificação no capitalismo global. In: PADILHA, V. (org.). Dialética do lazer. São Paulo: Cortez, 2006, p. 19 - 49.

BAUMAN, Z. A cultura no mundo líquido moderno. Tradução de Carlos Alberto Medeiros. Rio de Janeiro: Zahar, 2013.

. Danos Colaterais: desigualdades sociais numa era global. Tradução de Carlos Alberto Medeiros. Rio de Janeiro: Zahar, 2013. BOURDIEU, P. O poder simbólico. Rio de Janeiro: Bertrand Brasil, 1989.

BUCCI, E. Do rolezinho ao rolezaço. Revista Época. Edição 816. Semanal. São Paulo: Editora Globo, 18 a 24 de janeiro de 2014. BRASIL. Constituição da República Federativa do Brasil de 1988. Disponível em: <http://www.planalto.gov.br/ccivil_03/constituicao/ constituicaocompilado.htm>. Acesso em: 03 mar. 2014.

; Lei $n^{\circ}$. 12.852 de 05/08/2013: institui o Estatuto da Juventude e dispõe sobre os direitos dos jovens, os princípios e diretrizes das políticas públicas de juventude e o Sistema Nacional de Juventude. Disponível em: <http://www.planalto.gov.br/ccivil_03/_Ato20112014/2013/Lei/L12852.htm>. Acesso em: 03 mar. 2014.

CALLIARI, M.; MOTTA, A. Código Y: decifrando a geração que está mudando o país. São Paulo: Évora, 2012.

CASSAB, M. A. T.; CASSAB, C. Jovens e oportunidades: a desnaturalização da cidade desigual. Serviço Social \& Sociedade. São Paulo, $\mathrm{n}^{\circ} .83$, p. $49-62$, set. 2005.

CATANI, A. M.; GILIOLI, R. de S. P. Culturas juvenis: múltiplos olhares. São Paulo: Ed. Unesp, 2008. Coleção paradidáticos. FILHO, J. C. de M. O direito constitucional de reunião. Disponível em: 〈http://www.justitia.com.br/revistas/3w36db.pdf>. Acesso em: 03 mar. 2014.

FUCS, J. Os rolezinhos e o festival de besteiras que assola o país. Blog do Fucs. Revista Época. Edição 816. Semanal. São Paulo: Editora 
Globo, 18 a 24 de janeiro de 2014.

LEAL, M. C. O Estatuto da Criança e do Adolescente e a Lei de Diretrizes e Bases da Educação como marcos inovadores de políticas sociais. In: SALES, M. A.; MATOS, M. C.; Política social, família e juventude: uma questão de direitos. São Paulo: Cortez,

2010, p. $147-164$.

LIPOVETSKY, G. A felicidade paradoxal: ensaio sobre a sociedade de hiperconsumo. São Paulo: Companhia das Letras, 2007.

LOPES, J. R. Pobreza, subjetividade e cidadania. Serviço Social \& Sociedade. São Paulo, n. 70, p. 160 - 172, jul. 2002.

MARTÍN-BARBERO, J. A mudança na percepção da juventude: sociabilidades, tecnicidades e subjetividades entre os jovens. In: BORELLI, S. H.S.; FILHO, J. F. (Orgs.). Culturas juvenis no século XXI. São Paulo: EDUC, 2008.

NEITSCH, J. A legalidade do rolezinho, Gazeta do Povo. Disponível em: <http://www.gazetadopovo.com.br/vidapublica/justicadireito/ conteudo.phtml?id=1441716>. Acesso em: 03 mar. 2014.

NUNOMURA, E.; SANCHES, P. A. Rolezinhos de A a Z. Blog Farofafá. Carta Capital. Disponível em: <http:// farofafa.cartacapital.com.br/2014/01/28/rolezinho-de-a-a-z/>. Acesso em: 03 mar. 2014.

REDAÇÃO Época. O que a imprensa internacional diz sobre os rolezinhos, ou "little strolls". Revista Época. Edição 816. Semanal. São Paulo: Editora Globo, 18 a 24 de janeiro de 2014.

RIBEIRO, A.; et. al. Como começou a onda do rolezinho. Revista Época. Edição 816. Semanal. São Paulo: Editora Globo, 18 a 24 de janeiro de 2014.

ROSENFIELD, D. L. Decifrando os rolezinhos. O Globo. Disponível em: <http://oglobo.globo.com/opiniao/decifrando-os-rolezinhos11401425>. Acesso em: 03 mar. 2014.

ROUSSEAU, J. O contrato social: princípios do direito político. 3. ed. Tradução de Antônio de Pádua Danesi. São Paulo: Martins Fontes, 1996. Clássicos.

ROVER, T.; SCOCUGLIA, L. Juizes de SP e RJ têm posições antagônicas sobre "rolezinhos". Portal Consultor Jurídico. Disponível em: <http://www.conjur.com.br/2014-jan-20/juizes-sp-rj-posicoes-antagonicas-casos-rolezinhos>. Acesso em: 16 mar. 2014.

SCHERER, G. A. Serviço Social e arte: juventudes e direitos humanos em cena. São Paulo: Cortez, 2013.

SERRANO, P. E. "Rolezinho", capitalismo e gente bonita. Carta Capital. Online. Publicação de 17 de janeiro de 2014. Disponível em: <http://www.cartacapital.com.br/sociedade/rolezinho-capitalismo-e-gente-bonita-6318.html>. Acesso em: 15 mar. 2014.

SINGER, P. A juventude como coorte: uma geração em tempos de crise social. In: ABRAMO, H. W.; BRANCO, P. P. M. Retratos da juventude brasileira: análises de uma pesquisa nacional. São Paulo: Fundação Perseu Abramo/Instituto Cidadania, 2011, p. 27 - 35.

SILVA, L. R. Na mira da mídia: reflexões sobre as relações entre mídia, crime e identidade. In: SALES, M. A.; RUIZ, J. L. de S. (Orgs). Mídia, questão social e Serviço Social. São Paulo: Cortez, 2009.

SILVA, T. R. da. Musicalidade e territórios da pobreza: juventude, periferia e manifestação popular através dos raps de MV Bill. In: Seminário Nacional de Gestão de Políticas Sociais e Território, 1, 2013. Londrina. Anais... Londrina: UEL, 2013, p. 1-11.

; LEHFELD, N. A. S. Na batida do funk, a violência juvenil: a criminalização da juventude como um híbrido controverso. In: Congresso Internacional Mentalidades e Trabalho "Ética e Sociedade na Contemporaneidade", 1, 2014. Franca. Anais... Franca: UNESP, 2014, p. 375-384.

TRIBUNAL de Justiça do Estado de São Paulo. Decisão/Mandado - interdito proibitório: rolezinho no Shopping e outros. Foro Regional de Itaquera. São Paulo, 2013. Disponível em: 〈http://s.conjur.com.br/dl/rolezinho-metro-itaquera-dezembro.pdf>. Acesso em: 16 mar. 2014.

Decisão-interdito proibitório: rolezinho no shopping Iguatemi e outros. Foro de Campinas. Campinas, 2014. Disponível em: <http://s.conjur.com.br/dl/rolezinho-iguatemi-campinas.pdf>. Acesso em: 16 mar. 2014.

UNESCO. Declaração Universal dos Direitos Humanos de 1948. Brasília: Unesco Brasil, 1998. Disponível em: <http:// unesdoc.unesco.org/images/0013/001394/139423por.pdf >. Acesso em: 10 mar. 2014.

YAZBEK, M. C. Classes subalternas e assistência social. São Paulo: Cortez, 2009.

\section{Notas}

1 As gerações de pessoas consistem em uma organização cronológica de nascimentos em variados períodos, iniciando no final do século 19, com prosseguimento até o momento atual. O que distingue uma geração da outra são os fatos históricos vividos por cada uma, desenvolvimento social e tecnológico e apropriação destes desenvolvimentos pelas pessoas. Não há limite exato no tempo inicial e final de cada geração, sendo suas divisões flexíveis considerando um espaço de tempo de 15 a 20 anos.

2 Geração compreendida entre nascidos no final da década de 1970 ao início da década de 1990.

3 Geração compreendida entre nascidos no final da década de 1990 ao início da década de 2010.

4 Comunidades virtuais que se caracterizam por apresentar identidade específica, como gosto musical, pessoal, fã clubes e outras atividades diversas. Estas fan pages são curtidas e compartilhadas por pessoas de faixas etárias variadas que são adeptas às ideias lá promovidas. São espaços que visam discutir as opiniões das pessoas sobre o tema central daquela página.

5 Vertente paulista da música carioca, este gênero poetiza e exalta a temática do consumo, das marcas de grife, bens de alto custo e a relação destas no cotidiano de jovens das periferias, que se apresentam com pompa e luxo, na busca por status, pertencimento e reconhecimento social. 
6 É a pessoa que promove o evento, fazendo a sua divulgação.

7 Os ídolos dos "rolezeiros" também são jovens que vivem em comunidades das periferias, que ganham popularidade mediante postagens de vídeos caseiros na internet, usam roupas de grifes, possuem estética corporal atraente, se embelezam através das caras e bocas em fotos que são postadas, curtidas e compartilhadas nas redes sociais, enfim, são jovens que criam e ditam moda nos territórios periféricos.

8 Nome atribuído ao grupo de jovens que frequentam os rolezinhos.

\section{Neide Aparecida de Souza Lehfeld}

nlehfeld@unaerp.br

Doutora em Serviço Social pela Pontifícia Universidade Católica de São Paulo (PUC-SP)

Docente na Universidade Estadual Paulista Júlio de Mesquita Filho (UNESP-Franca)

\section{Thiago Rodrigo da Silva}

asocial.thiago@gmail.com

Mestre em Serviço Social pela Universidade Estadual Paulista Júlio de Mesquita Filho (UNESP/Franca)

Assistente Social da Comunidade Missionária Divina Misericórdia de Batatais/SP

\section{UNESP}

Av. Eufrásia Monteiro Petráglia, 900, Jardim Dr. Antônio Petráglia

Franca - São Paulo - Brasil

CEP: $14409-160$

\section{Comunidade Missionária Divina Misericórdia}

Rua Dr Égas Muniz, 179 - Central Park

Batatais - São Paulo - Brasil

CEP: 14300-000 